\title{
An Emerging Application of Cholesterol-lowering Therapy in Inhibition of Rotavirus Infection
}

Shihao Ding ( $\nabla$ tingtingv25@gmail.com )

Erasmus Medical Centre: Erasmus MC https://orcid.org/0000-0002-0490-3608

\section{Bingting Yu}

Erasmus Medical Centre: Erasmus MC

Anneke van Vuuren

Erasmus Medical Centre: Erasmus MC

Keywords:

Posted Date: August 30th, 2021

DOl: https://doi.org/10.21203/rs.3.rs-833175/v1

License: (c) (1) This work is licensed under a Creative Commons Attribution 4.0 International License. Read Full License 


\section{Abstract}

The authors have requested that this preprint be removed from Research Square. 